\title{
Evaluation of Fast Disintegrating Tablets of Nifedipine Prepared by Superdisintegrant Addition and Sublimation Methods
}

\author{
Eraga Sylvester Okhuelegbe, Arhewoh Matthew Ikhuoria \\ and Ajah Anthony Ike
}

Department of Pharmaceutics and Pharmaceutical Technology, Faculty of Pharmacy, University of Benin, Benin City, 300001, Nigeria

Received: June 08, 2014; Accepted: November 24, 2014; Published (web): December 31, 2014

\begin{abstract}
Fast disintegrating tablets of nifedipine prepared by superdisintegrant addition and sublimation methods were evaluated. Twelve batches of tablets were formulated by direct compression using varying concentrations of crospovidone and croscarmellose sodium. Camphor was incorporated into six of the batches. Their granules were evaluated for pre-compression and post-compression parameters. FTIR analysis of the drug and excipients was also carried out. Results obtained showed that their granules were free flowing with angle of repose < $26^{\circ}$ and Carr's index $<19 \%$. The tablets gave hardness of 3.67-5.99 kgf, friability of $<1 \%$, wetting and disintegration times of $<101$ and $<91$ secs, respectively. Dissolution profiles showed all the tablets released over 92 $\%$ of their drug within 30 mins. FTIR analysis demonstrated no interactions between nifedipine and excipients. The sublimation method in combination with superdisintegrant addition method of formulation yielded fast disintegrating tablets of superior quality than the superdisintegrant addition method alone.
\end{abstract}

Key words: Nifedipine, superdisintegrant, sublimation, post-compression, dissolution

\section{INTRODUCTION}

Fast disintegrating tablets (FDTs) are gaining popularity as drug delivery system and emerging as one of the popular and widely accepted dosage forms, especially for the paediatric and geriatric patients. To obviate the problems of dysphagia and to improve patient compliance, FDTs have achieved considerable attention as preferred alternatives to conventional tablet and capsule formulations. ${ }^{1}$

Various scientific techniques have been employed in the developments of FDTs such as direct compression, wet granulation, moulding, spray drying, freeze drying, sublimation etc. Several technologies for the manufacturing of FDTs have been patented and already been used for commercial products in the market because of their advantages

Correspondence to: Eraga Sylvester Okhuelegbe

Tel: +2348030884928; E-mail: eragaso@uniben.edu

Dhaka Univ. J. Pharm. Sci. 13(2): 199-205, 2014 (December) which includes quick dissolution, increased bioavailability, improved taste masking, high surface area, faster and efficient production. However, they have several drawbacks which include: expensive process, poor stability at high temperature and humidity, low mechanical strength and inconvenience with larger dose. . $^{2-6}$

Sublimation and superdisintegrant addition methods have been employed in many research works as they are cost effective, utilizes conventional equipments and produces FDTs with good disintegrating properties. $^{7-9}$

Nifedipine is a calcium channel blocker. It acts through blocking of $\mathrm{Ca}^{2+}$ entry by preventing opening of voltage gated L- type calcium channels. Nifedipine can be used in the management of hypertension, angina pectoris and uncomplicated preterm labour. ${ }^{10}$ 
The present study was designed to evaluate the fast disintegrating tablets of nifedipine prepared by superdisintegrant addition and sublimation methods.

\section{MATERIALS AND METHODS}

Nifedipine powder was a gift from Gemini Pharmaceuticals, Lagos State, Nigeria, croscarmellose sodium and aspartame (BDH UK), crospovidone (ISP Technologies Incorporated, NJ, USA), talc (Evans Medical Ltd, Liverpool), camphor (Fluka Chemicals, Switzerland), microcrystalline cellulose and magnesium stearate (Edo Pharmaceuticals, Benin City, Nigeria), Nifecard 20 mg retard (CB1) (Salutas Pharma GmbH, Germany), Nifedin Dexcel 20 mg retard (CB2) (Dexcel Limited, Israel).

Preparation of tablets. Various batches of tablets were prepared using the formula depicted in table 1 under subdued light. Twelve (12) batches (A1-A6 and B1-B6) of nifedipine containing two superdisintegrants, croscarmellose sodium and crospovidone in different proportions were prepared using microcrystalline cellulose (MCC) as diluent. Camphor was included in B1-B6 batches as a subliming agent. The ingredients of each batch were weighed and passed through a \#710 mesh screen (Endecotts, England) prior to mixing. The screened quantities of nifedipine, croscarmellose sodium, crospovidone, aspartame, microcrystalline cellulose and camphor were transferred into a mortar and mixed intimately with a pestle. Specific screened quantities of magnesium stearate and talc were added stepwise and mixed thoroughly. The powder blend was slugged using a heavy-duty tableting machine (Karl Kolh Technical Supplies, Germany) and the resulting tablets were broken up into granules with a mortar and pestle. The granules were evaluated for pre-compression parameters and then compressed into tablets using a single punch tablet machine (Manesty Machines, UK) at a pressure of 30 arbitrary units (AU). B1-B6 batches tablets were dried at $60^{\circ} \mathrm{C}$ for $8 \mathrm{~h}$ (for the sublimation of camphor) until a constant weight was obtained to ensure complete removal of the subliming agent and to give tablets that are porous in their structure. A control batch (AB) containing none of the superdisintegrants and camphor was also prepared. Tablets from various batches were evaluated for post-compression parameters. One hundred tablets were prepared per batch.

Evaluation of the prepared granules. The granules were subjected to the following evaluation: angle of repose, bulk and tapped densities according to official requirements/specifications under subdued light. Compressibility (Carr's index) and Hausner's factor were thereafter calculated (Table 2).

Compatibility studies. The drug-excipients interactions were studied using a Fourier Transform Infrared Spectrophotometer (Spectrum BX, Perkin Elmer, England). Using potassium bromide ( $\mathrm{KBr})$ pellet method, the drug, excipients and powdered tablets were scanned at a range of $4000-350 \mathrm{~cm}^{-1}$.

Table 1. Formula for the preparation of different batches of nifedipine tablets.

\begin{tabular}{|c|c|c|c|c|c|c|c|c|c|c|c|c|c|}
\hline \multirow{2}{*}{ Ingredients } & \multicolumn{13}{|c|}{ Batches } \\
\hline & A1 & $\mathrm{A} 2$ & A3 & A4 & A5 & A6 & B1 & B2 & B3 & B4 & B5 & B6 & $\mathrm{AB}$ \\
\hline Nifedipine & 5 & 5 & 5 & 5 & 5 & 5 & 5 & 5 & 5 & 5 & 5 & 5 & 5 \\
\hline Croscarmellose sodium & 5 & - & 5 & 10 & 5 & 10 & 5 & 10 & 5 & 10 & 5 & 10 & - \\
\hline Crospovidone & - & 5 & 5 & 5 & 10 & 10 & 5 & 10 & 5 & 10 & 5 & 10 & - \\
\hline Aspartame & 4 & 4 & 4 & 4 & 4 & 4 & 4 & 4 & 4 & 4 & 4 & 4 & 4 \\
\hline Magnesium stearate & 3 & 3 & 3 & 3 & 3 & 3 & 3 & 3 & 3 & 3 & 3 & 3 & 3 \\
\hline Talc & 3 & 3 & 3 & 3 & 3 & 3 & 3 & 3 & 3 & 3 & 3 & 3 & 3 \\
\hline Microcrystalline cellulose & 130 & 130 & 125 & 120 & 120 & 115 & 120 & 110 & 115 & 105 & 110 & 100 & 135 \\
\hline Camphor & - & - & - & - & - & - & 5 & 5 & 10 & 10 & 15 & 15 & - \\
\hline Total weight/tablet & 150 & 150 & 150 & 150 & 150 & 150 & 150 & 150 & 150 & 150 & 150 & 150 & 150 \\
\hline
\end{tabular}

All quantities are in $\mathrm{mg}$ 
Table 2. Micromeritic properties of different batches of granules.

\begin{tabular}{cccccc}
\hline Batch & $\begin{array}{c}\text { Bulk } \\
\text { density } \\
\left(\mathrm{g} / \mathrm{cm}^{3}\right)\end{array}$ & $\begin{array}{c}\text { Tapped } \\
\text { density } \\
\left(\mathrm{g} / \mathrm{cm}^{3}\right)\end{array}$ & $\begin{array}{c}\text { Angle of } \\
\text { repose }\left({ }^{\circ}\right)\end{array}$ & $\begin{array}{c}\text { Carr's } \\
\text { index }(\%)\end{array}$ & $\begin{array}{c}\text { Hausner's } \\
\text { ratio }\end{array}$ \\
\hline A1 & $0.3112 \pm 0.02$ & $0.3661 \pm 0.03$ & $22.27 \pm 0.11$ & $14.99 \pm 0.11$ & $1.176 \pm 0.11$ \\
A2 & $0.3234 \pm 0.02$ & $0.3832 \pm 0.02$ & $23.34 \pm 0.12$ & $15.61 \pm 0.10$ & $1.185 \pm 0.12$ \\
A3 & $0.3184 \pm 0.05$ & $0.3627 \pm 0.01$ & $23.15 \pm 0.11$ & $13.59 \pm 0.02$ & $1.157 \pm 0.11$ \\
A4 & $0.3123 \pm 0.01$ & $0.3814 \pm 0.01$ & $25.33 \pm 0.11$ & $18.12 \pm 0.02$ & $1.221 \pm 0.11$ \\
A5 & $0.3164 \pm 0.03$ & $0.3638 \pm 0.02$ & $24.56 \pm 0.12$ & $13.03 \pm 0.02$ & $1.150 \pm 0.12$ \\
A6 & $0.3269 \pm 0.02$ & $0.3792 \pm 0.04$ & $24.12 \pm 0.15$ & $13.79 \pm 0.06$ & $1.160 \pm 0.15$ \\
B1 & $0.3126 \pm 0.02$ & $0.3648 \pm 0.04$ & $23.15 \pm 0.12$ & $14.31 \pm 0.03$ & $1.167 \pm 0.12$ \\
B2 & $0.3111 \pm 0.04$ & $0.3531 \pm 0.01$ & $24.58 \pm 0.11$ & $11.89 \pm 0.01$ & $1.135 \pm 0.11$ \\
B3 & $0.3113 \pm 0.01$ & $0.3772 \pm 0.03$ & $25.25 \pm 0.13$ & $17.47 \pm 0.10$ & $1.212 \pm 0.10$ \\
B4 & $0.3256 \pm 0.02$ & $0.3749 \pm 0.02$ & $23.80 \pm 0.15$ & $13.15 \pm 0.05$ & $1.151 \pm 0.12$ \\
B5 & $0.3261 \pm 0.03$ & $0.3863 \pm 0.01$ & $22.13 \pm 0.12$ & $15.58 \pm 0.02$ & $1.185 \pm 0.15$ \\
B6 & $0.3145 \pm 0.01$ & $0.3595 \pm 0.02$ & $22.43 \pm 0.11$ & $12.58 \pm 0.03$ & $1.143 \pm 0.12$ \\
AB & $0.3246 \pm 0.02$ & $0.3785 \pm 0.03$ & $25.23 \pm 0.12$ & $14.24 \pm 0.02$ & $1.166 \pm 0.11$ \\
\hline
\end{tabular}

Evaluation of tablets. The following tests were carried out on the compressed tablets using standard procedures: tablet weight uniformity, hardness and friability. ${ }^{11}$

Tablet dimensions. The thickness and diameter of the tablets were measured using a micrometer screw guage (Gallenkamp, England). Twenty (20) tablets from each batch were randomly chosen and their thickness and diameter measured individually.

Uniformity of weight. Twenty (20) tablets were randomly selected from each batch and their weights were determined individually on a digital weighing balance (College B154, Mettler Toledo, Switzerland). The mean weights and standard deviation were determined.

Tablets hardness. The hardness of ten (10) randomly selected tablets per batch was determined using Campbell Electronics Hardness Tester (HT30/50, India). The mean values and standard deviation was calculated from each batch.

Friability test. The weight of ten (10) tablets was determined on the electronic balance. The tablets were then placed in the drum of a Roche Erweka Friabilator revolving at $25 \mathrm{rpm}$ which exposes the tablets to abrasion from rolling and repeated free falls within the apparatus. After four minutes, the tablets were brought out and reweighed after being dedusted. The weight was then recorded and friability calculated as percentage loss in weight.
Wetting time. A piece of double folded tissue paper was placed in a petridish containing $6 \mathrm{~mL}$ of water. The tablet was placed on the paper and the time for complete wetting of the tablet surface was measured in seconds. ${ }^{12}$

Disintegration test. The disintegration time for all formulations was carried out using a tablet disintegration test apparatus (Manesty Machines Ltd, UK). A tablet was placed in each of the six tubes of the apparatus and the discs were placed. Distilled water used as the disintegration medium was maintained at $37^{\circ} \mathrm{C}$ and the time taken for the entire tablet to disintegrate completely was measured in seconds.

Calibration curve for nifedipine. Various nifedipine standard concentrations ranging from 1.0 $10 \mu \mathrm{g} / \mathrm{ml}$ were prepared from stock solutions and subjected to ultra-violet spectrophotometric analysis at $350 \mathrm{~nm}$ (UNICO $\left.{ }^{\mathrm{TM}} 2100\right)$ under subdued light. Respective absorbances were taken and lines of regression were determined. The calibrator prepared in methanol was used for assay of the active drug, while that in $0.1 \mathrm{M} \mathrm{HCl}$ was used for the analysis of the dissolution samples. The assay and analysis of the dissolution samples were also carried out under subdued light.

Content of active drug. Twenty (20) tablets were randomly selected from each sample and crushed to fine powder. A quantity of the powdered tablets equivalent to $5 \mathrm{mg}$ nifedipine was weighed 
and dissolved in $50 \mathrm{ml}$ of methanol in a $100 \mathrm{ml}$ volumetric flask. The volume was made up with more methanol. Necessary dilutions were carried out to obtain a final concentration of $100 \mu \mathrm{g} / \mathrm{ml}$, the solution was thereafter filtered through a Whatman \#1 filter paper and the absorbance of the filtrate was determined at $350 \mathrm{~nm}$ using methanol as blank.

Dissolution studies. The dissolution tests were carried out using a BP Dissolution Test Apparatus (Caleva ST7, UK). This was fitted with a basket rotated at $100 \mathrm{rpm}$ using $900 \mathrm{~mL}$ of $0.1 \mathrm{M} \mathrm{HCl}$ solution as dissolution medium maintained at $37 \pm$ $0.5{ }^{\circ} \mathrm{C}$. Six (6) tablets selected randomly from each batch were used simultaneously for the study. A $5 \mathrm{ml}$ volume of leaching fluid was withdrawn at $1 \mathrm{~min}$ intervals for the first $5 \mathrm{mins}$ and then at $5 \mathrm{mins}$ intervals for 30 mins. The withdrawn fluid was replaced with an equivalent volume of the test medium maintained at the same temperature (37 \pm $0.5^{\circ} \mathrm{C}$ ). The aliquot was filtered and diluted with an equal volume of $0.1 \mathrm{M} \mathrm{HCl}$. The absorbances of the resulting solutions were measured at $\lambda \max 350 \mathrm{~nm}$ by using the UV/Visible spectrophotometer. The percentage of drug released was then calculated. The dissolution profiles of two commercially available nifedipine tablets were also carried out for comparison.

Statistical analysis. Descriptive statistics was done for all data using Microsoft Excel (2007). Mean and standard deviations of triplicate determinations were computed and reported. Differences between mean was determined using ANOVA while $p>0.05$ was considered significant.

\section{RESULTS AND DISCUSSION}

Properties of granules. The angle of repose for all the batches of granules was within the range of $22.13^{\circ}$ to $25.33^{\circ}$ and compressibility index was found to be in the range $12.58 \%$ to $18.12 \%$ while the Hausner's ratio of the batches were in the range of 1.135 to 1.221 . BP specifies that an angle of repose between $20^{\circ}$ to $30^{\circ}$ and Hausner's ratio of $<1.25$ as indicative of good flow properties. This shows that the granules from all the batches exhibited good flowability.

Tablet properties. The result of tablet properties is shown in table 3 . All the formulated tablets passed the weight variation test (due to uniform die fill) as the variation was within the BP limits of $\pm 7.5 \%$ of the weight. The hardness of the entire tablets was within the range of 3.67 to $5.99 \mathrm{kgf}$. The friability of the formulations ranged from 0.22 to $0.74 \%$ while disintegration time was $<91 \mathrm{sec}$ for all the test products.

Compatibility studies. The infrared (IR) spectra of pure nifedipine, formulations $\mathrm{A}$ and $\mathrm{B}$ are shown in figures $3 \mathrm{a}, \mathrm{b}$ and $\mathrm{c}$. All principal IR peaks of nifedipine were present and similar in all cases. This clearly indicates that there was no decomposition or chemical interaction between nifedipine and the excipients.

The weights of all the tablets were uniform with low standard deviation values while the tablets exhibited satisfactory hardness but those of batches B1-B6 had the least hardness values. This could be due to the porous matrix created within the tablets by the sublimation of camphor. All the tablets passed the friability test as the percentage friability was below $1 \%$ and thus were considered acceptable. Furthermore, batches B1-B6 showed higher percentage friability than batch A1-A6 because they exhibited lower tensile strength (hardness) and probably due to the porous structure of the tablet matrix as described by Shinde $e t$ al. ${ }^{13}$

The wetting time for all the tablets was within 35 to $101 \mathrm{sec}$ except for tablets from the control batch $A B$ with wetting time above 6 mins. However, the batches B1-B6 tablets showed minimal wetting time than those of batches A1-A6. From all formulations, B5 had the least wetting time (10 secs). The very low wetting time exhibited by all the tablets could be due to the two superdisintegrants (croscarmellose sodium and crospovidone) through the mechanisms of swelling and wicking described by Shirland et al. ${ }^{14}$ However, batches B1-B6 tablets gave faster disintegration values because of the combined effects of the superdisintegrants and the porous structure 
within the tablet matrix from the sublimation of camphor.

From the results in Table 3, tablets in batches A1-A6 disintegrated within 56-91 sec and the batches B1-B6 tablets within 33-58 sec, while the control batch $\mathrm{AB}$ disintegrated after $5 \mathrm{~min}$. The batches $\mathrm{A}$ and $\mathrm{B}$ tablets exhibited minimum disintegration time due to the combined effect of swelling and water absorption conferred on them by the superdisintegrants. Due to the swelling of crospovidone and croscarmellose sodium, the wetted surface of the carrier increased. This promotes the wettability and dispersibility of the system, thus enhancing their disintegration. However, batch B has an added advantage of a subliming agent (camphor) incorporated into it which created a porous structure in the tablet thereby enhancing its disintegration. This is in accordance with previous work done by Shinde et al. ${ }^{13}$ Formulation B5 has the least disintegration time at a croscarmellose sodium concentration of 5 $\mathrm{mg}$, crospovidone concentration of $5 \mathrm{mg}$ and camphor concentration of $15 \mathrm{mg}$ (1:1:3) which proved to be optimal. Batch B6 followed closely with disintegration time of 41 secs and then B3 with 44 secs. Moreover, A1 presented the highest disintegration time 91 secs. The control batch $\mathrm{AB}$ disintegrated within the acceptable time of less than 6 mins because of the inherent disintegrant properties of microcrystalline cellulose (MCC) that was used as diluent in all the tablets.

Table 3. Post compression parameters of the formulated tablets.

\begin{tabular}{cccccccc}
\hline Batch & $\begin{array}{c}\text { Tablet } \\
\text { weight }(\mathrm{mg})\end{array}$ & $\begin{array}{c}\text { Tensile } \\
\text { strength } \\
(\mathrm{kgf})\end{array}$ & $\begin{array}{c}\text { Friability } \\
(\%)\end{array}$ & $\begin{array}{c}\text { Disintegration } \\
\text { time }(\mathrm{sec})\end{array}$ & $\begin{array}{c}\text { Wetting } \\
\text { time }(\mathrm{sec})\end{array}$ & $\begin{array}{c}\text { Drug } \\
\text { content }(\%)\end{array}$ & $\begin{array}{c}\text { Dissolution } \\
\text { efficiency } \\
(\%)\end{array}$ \\
\hline A1 & $151.2 \pm 0.63$ & $5.34 \pm 0.32$ & 0.34 & $91 \pm 0.13$ & $101 \pm 0.63$ & $99.05 \pm 0.21$ & $\begin{array}{c}\text { T 50\% } \\
(\mathrm{min})\end{array}$ \\
A2 & $150.1 \pm 0.98$ & $5.99 \pm 0.29$ & 0.22 & $79 \pm 0.04$ & $87 \pm 0.61$ & $98.82 \pm 0.15$ & 97 \\
A3 & $149.5 \pm 0.63$ & $5.16 \pm 0.21$ & 0.41 & $72 \pm 0.02$ & $84 \pm 0.20$ & $99.42 \pm 0.11$ & 95 \\
A4 & $151.4 \pm 0.81$ & $5.18 \pm 0.49$ & 0.46 & $83 \pm 0.03$ & $92 \pm 0.82$ & $99.10 \pm 0.22$ & 96 \\
A5 & $150.8 \pm 0.53$ & $5.66 \pm 0.24$ & 0.35 & $56 \pm 0.02$ & $66 \pm 0.13$ & $99.13 \pm 0.15$ & 93 \\
A6 & $150.9 \pm 0.58$ & $5.24 \pm 0.21$ & 0.40 & $60 \pm 0.04$ & $73 \pm 0.80$ & $99.03 \pm 0.11$ & 96 \\
B1 & $150.8 \pm 0.59$ & $4.78 \pm 0.22$ & 0.59 & $58 \pm 0.05$ & $61 \pm 0.04$ & $100.18 \pm 0.22$ & 96 \\
B2 & $150.7 \pm 0.10$ & $4.69 \pm 0.15$ & 0.61 & $52 \pm 0.14$ & $60 \pm 0.95$ & $99.50 \pm 0.21$ & 95 \\
B3 & $152.0 \pm 0.90$ & $4.27 \pm 0.24$ & 0.65 & $44 \pm 0.03$ & $48 \pm 0.15$ & $99.15 \pm 0.15$ & 3 \\
B4 & $157.7 \pm 0.57$ & $4.31 \pm 0.27$ & 0.66 & $51 \pm 0.02$ & $54 \pm 0.85$ & $99.18 \pm 0.22$ & 97 \\
B5 & $151.9 \pm 0.26$ & $3.67 \pm 0.23$ & 0.73 & $33 \pm 0.05$ & $35 \pm 0.35$ & $100.02 \pm 0.11$ & 94 \\
B6 & $151.3 \pm 0.50$ & $3.81 \pm 0.11$ & 0.74 & $41 \pm 0.01$ & $47 \pm 0.48$ & $99.82 \pm 0.21$ & 99 \\
AB & $150.1 \pm 0.50$ & $5.87 \pm 0.31$ & 0.62 & $325 \pm 0.07$ & $365 \pm 0.87$ & $99.65 \pm 0.14$ & 98 \\
\hline
\end{tabular}

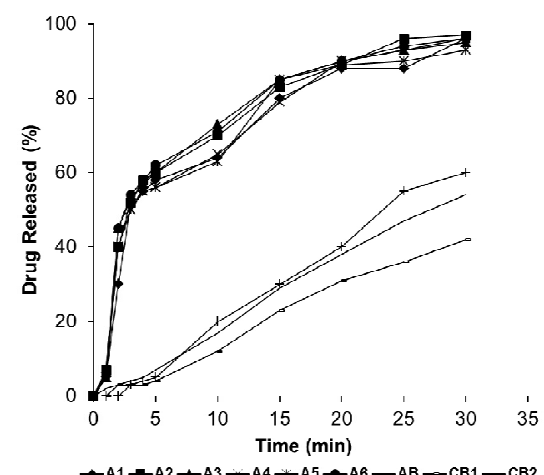

Figure 1. Drug release profile of batch A tablets and the commercial brands (CB).

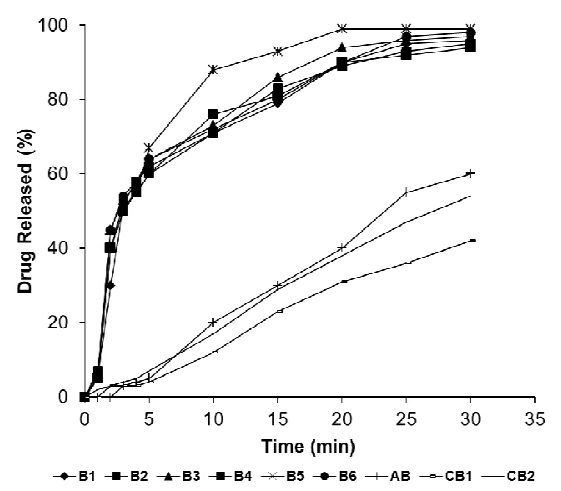

Figure 2. Drug release profile of batch $B$ tablets and the commercial brands (CB). 


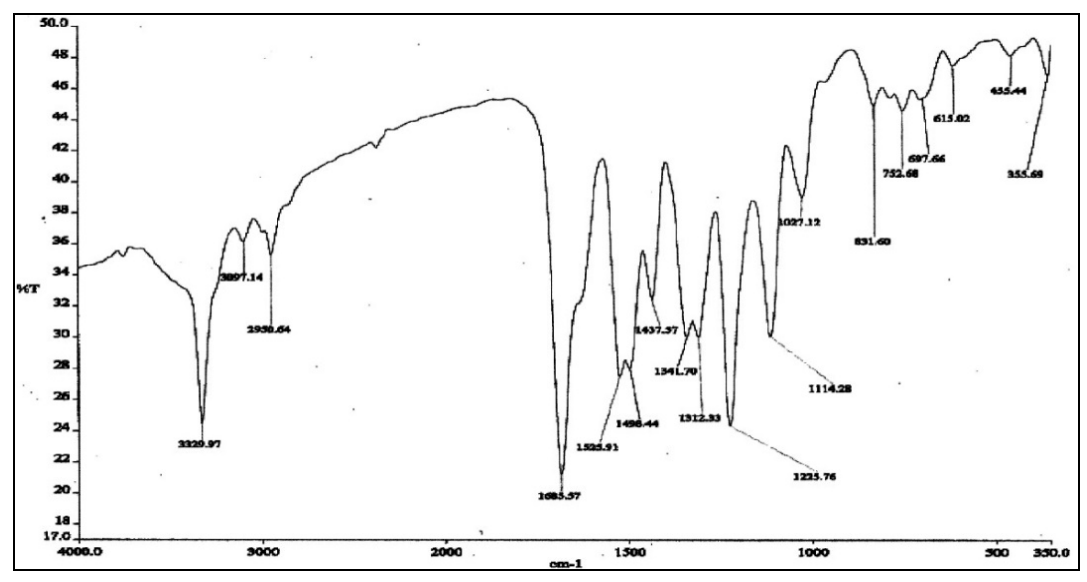

Figure 3a. FTIR spectrum of nifedipine.
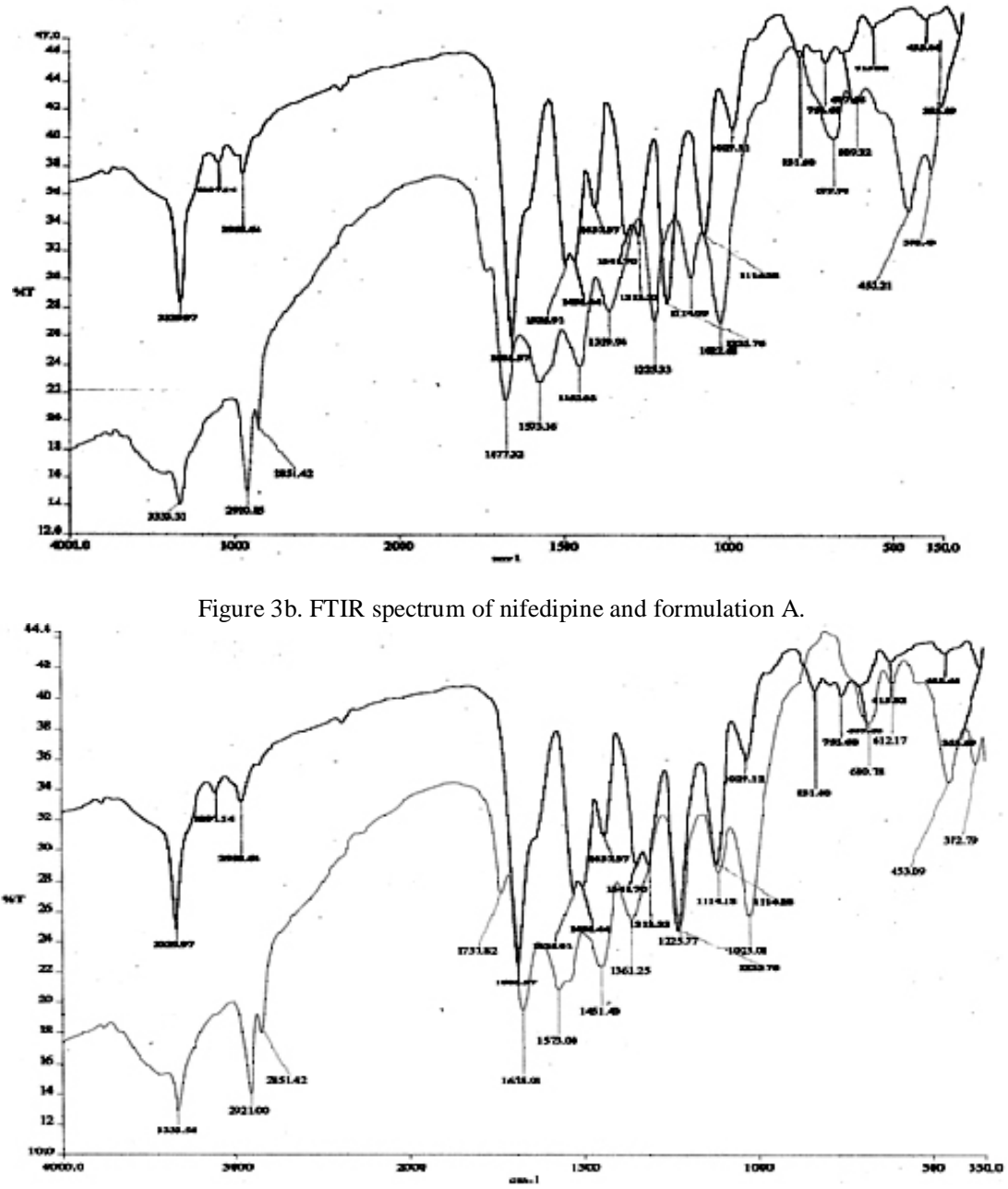

Figure 3c. FTIR spectrum of nifedipine and formulation B.

The dissolution test is the most important way to study the release of a drug from a solid dosage form under in vitro condition, which correlates with in- vivo conditions ideally. For a drug which has poor aqueous solubility, the rate at which it dissolves in the gastrointestinal fluid is often the slowest step and 
the bioavailability of that drug is said to be dissolution rate limited. Unless a drug substance is released into the dissolution medium upon disintegration, absorption cannot take place. The drug release profiles of the formulations are presented in Figures 1 and 2 . The entire fast disintegrating tablet formulations released more than $50 \%$ of the drug within 3 mins (Table 3) and $90 \%$ within 20 mins except the control batch of tablets with $20 \%$ in 10 mins and $60 \%$ in 30 mins. These values are actually possible due to the rapid disintegration of the tablets which in turn facilitates the dissolution process. The drug release profile of the batch $B$ series showed better prospects than batch A. As observed by Shinde et al. ${ }^{13}$, the addition of a subliming agent did not produce a significant improvement $(p>0.05)$ in the drug release profile of the formulation. Also, the two commercial products (CB1 and CB2) released $42 \%$ and $54 \%$ respectively of their medicament in 30 mins. These differences in the patterns of release must have been caused by manufacturers' choice of method of achieving reduction or delay in the rate of drug release, which could be achieved either by increase in particle size or formation of insoluble crystals. ${ }^{15}$ However, dissolution data shows that formulation B5 exhibits the best dissolution profile compared to other formulations with a T50\% of 1 min and $99 \%$ dissolution efficiency. Therefore, B5 was chosen as the formulation with the best prospect.

\section{CONCLUSION}

Camphor and superdisintegrants at varying concentrations were seen to significantly affect disintegration time, wetting time and dissolution profile. Batch B5 containing $5 \mathrm{mg}$ of crospovidone, 5 $\mathrm{mg}$ croscarmellose sodium and $15 \mathrm{mg}$ of camphor (1:1:3) was the most promising batch with disintegration time of $33 \mathrm{sec}$, wetting time of $35 \mathrm{sec}$ and $99 \%$ drug release at the end of 20 mins. This showed that the combination of superdisintegrant addition and sublimation method using camphor yielded FDTs with superior qualities than with superdisintegrant addition method alone.

\section{REFERENCES}

1. Sehgal, P., Gupta, R., Singh, U.K., Chaturvedi, A., Gulati, A. and Sharma, M. 2012. Fast dissolving tablets: a new venture in drug delivery. Am. J. Pharm. Tech. Res. 2, 233-279.

2. Sharma, R., Rajput, M., Pawan, P. and Sharma, S. 2012. Fast dissolving drug delivery system - a review. Int. Res. J. Pharm. 2, 21-29.

3. Shinde, A., Yadav, V., Gaikwad, V. and Dange, S. 2013. Fast disintegration drug delivery system - A review. Int. J. Pharm. Sci. Res. 4, 2548-2561.

4. Dincsh, V., Sharma, I. and Sharma, V. 2011. A comprehensive review on fast dissolving tablet technology. $J$. Appl. Pharm. Sci. 1, 50-58.

5. Reddy, D.R., Sai, R.C., Sesha, V., Saravan, K.T., Kumar, K.S., Reddy, V.Y., Kumari, C. and Taraka, L. 2011. Rapimelts: a review. J. Pharm. Biomed. Sci. 6, 1-8.

6. Kumari, S., Visht, S. and Sharma, P.K. 2010. Fast dissolving drug delivery system. J. Pharm. Res. 3, 1444-1449.

7. Mudgal, V.K., Sethi, P., Kheri, R., Saraogi, G.K. and Singhai, A.K. 2011. Orally disintegrating tablets: a review. Int. Res. J. Pharm. 2, 16-22.

8. Biswajit, B., Abhishek, B., Sagar, M., Vora, V., Devraj, B., and Abhay, D. 2011. Formulation and evaluation of fast dissolving tablets of cinnarizine using superdisintegrant blends and subliming material. J. Adv. Pharm. Technol. Res. 2, 266-273.

9. Narmada, G.Y., Mohini, K., Prakash, R.ao B., Gowrinath, D.X.P. and Kumar, K.S. 2009. Formulation, evaluation and optimization of fast dissolving tablets containing amlodipine besylate by sublimation method. Ars Pharm. 50, 129-144.

10. Katzung, B.G., Masters, S.B. and Trevor, A.J. 2009. Basic and Clinical Pharmacology. 11 $1^{\text {th }}$ Edition. Mc Graw Hill Medical, New York, pp. 199-201.

11. British Pharmacopoeia Vol I and Vol 11. 2003. The Pharmaceutical Press, Her Majesty's Stationery Office, London, pp. 249-252.

12. Lachman, L., Lieber, H.A. and Schwartz, J.B. 2005. Pharmaeutical dosage forms: Tablets, Vol I: Compressed Tablets by Wet Granulation, $2^{\text {nd }}$ edition, Marcel Dekker, New York, p. 241.

13. Shinde, A.J., Waghule, A.N., Paithane, A. and More, H.N. 2010. Development and characterization of oral fast dissolving tablets of nifedipine using camphor as a subliming material. Res. J. Pharm. Biol. Chem. Sci. 1, 46-50.

14. Shirland, S.B., Sarasija, S. and Swamy, P.V. 2009. Foundation design and optimization of fast dissolving clonazepam tablets. Indian J. Pharm. Sci. 71, 567-572.

15. Okoye, E.I. and Iwuagwu, M.A. 2010. Physicochemical equivalence of some brands of nifedipine retard tablets available in Nigeria. African J. Biotechnol. 9, 1274-1279. 